\title{
A Year in the Life of ACEN!
}

\section{Jessica Kerr}

Communications Specialist

Mary Ellen Jeans, RN, PhD

Secretary General

Academy of Canadian Executive Nurses
Once each year we publish the ACEN Annual Report in this column. This year is no exception, but first, an update on our recent annual education day and Annual General Meeting.

The ACEN education day was dedicated to leadership development. The day was facilitated by Leslie SouthwickTrask, who is well known for her success in fostering change and assisting groups, companies, boards and others to "think outside the box" and act as change agents. The theme for the day was "Nursing Leadershift," which prompted a very high level of interaction, emotional discomfort, humour and thoughtful discussion. People worked together in small groups, a format that encouraged personal communication and networking. There were 50 members of ACEN present, representing almost half the membership - a great turnout. The program is posted on our website at www.acen. ca. The day was followed by a reception and then dinner at a nearby restaurant. The AGM was held on the following day and was attended by 56 members. Reports were presented by President Wendy Hill, the committee chairs and the secretary general. There was good discussion of some of the policy positions, and suggestions were made for future policy considerations. Barb McGill, past president and chair of the nominating committee, announced that Carol Ringer had been voted president-elect for 2006-2007. Patty O'Connor and Diane Larrivee were named as the new chairs of the 
Membership and Governance committee and Policy committee, respectively. Mary Ellen Gurnham will continue as chair of the Leadership committee, and Mary Ferguson-Paré as chair of the Editorial Advisory Board of the journal. At the end of the meeting, Lynette Best and Louise Jones were thanked as outgoing committee chairs, and Leslie Vincent assumed her role as president of ACEN for 2006-2007. Wendy Hill was thanked for her leadership as president for the past year, as was Mary Ellen Jeans for her role as the first executive director of ACEN. Dr. Jeans completes her commitment to ACEN at the end of December. A new executive director will be named in the next few weeks.

The remainder of the meeting featured an excellent presentation on the Canadian Health Services Research Foundation (CHSRF) EXTRA program, a joint initiative between ACEN and the Association of Canadian Academic Healthcare Organizations (ACAHO). Patty O'Connor and Pierre Allard presented their experience of the program and described their projects. They were followed by their respective institutional spokespersons, who discussed the benefits of the program to the institution.

Later that evening, the Fall Invitational Conference of ACAHO began with a dinner and speaker (see program). The meeting continued the next day with some stimulating discussions led by political journalists, followed by thoughtful presentations on the challenges for the future of academic medicine. A large number of ACEN members stayed for the ACAHO meeting. Overall, the meetings were a great success. ACEN expresses its sincere gratitude to CHSRF, Johnson \& Johnson and the Office of Nursing Policy, Health Canada for their support and sponsorship. All of the detailed reports are posted on our website.

Now, a synopsis of this year's Annual Report.

\section{ACEN Annual Report: November 2005 to November 2006}

Overall, this has been a year of further growth and consolidation of ACEN as a key national organization. Membership has grown, revenues from membership and other sources have increased, activity has intensified and ACEN's visibility continues to improve. The four committees of the Academy have been highly productive. ACEN has been represented by its president at key national discussions, including a recent meeting with the federal Minister of Health. Other members of the executive committee and the secretary general have represented ACEN at numerous meetings of stakeholders and project partners throughout the year.

We have worked this year to improve communication with members. Our website was transferred to head office, and we have hired a consultant to redesign it to reflect our new logo and products. We will have a membersonly section, and member input will be sought on further improvements to the site over the next few months. The former listserv that was used by ACEN members has been discontinued and has been replaced by direct e-mail to members. 
The remainder of the Annual Report presents ACEN activities in relation to each of the objectives of the Academy.

\section{Objective 1: To influence and partici- pate in setting the directions for healthcare policy and dialogue in Canada}

The federal election and the change to the minority Conservative government significantly delayed the capacity of ACEN and all health-related NGOs to influence policy. The government led by Prime Minister Stephen Harper has remained at arm's length from national health organizations. There have been few meetings and few appearances by the Minister of Health, Tony Clement. Only recently has this situation begun to change, when ACEN, together with other national nursing associations, was invited to meet with the minister of health on October 26, 2006. This is the first time ACEN has been included as a national association to meet a federal minister.

Despite the lack of direct contact with federal politicians, ACEN has been working with other national organizations to influence policy. On the issue of healthcare leadership, ACEN has continued to work with the Canadian College of Health Service Executives (CCHSE) and the Canadian Society of Physician Executives (CSPE) to try to engage Health Canada and CHSRF in supporting the leadership project that began over two years ago. While Human Resources and Social Development Canada (HRSDC) declined to fund a health human resources sector study on healthcare leaders early in 2006, we have succeeded in achieving funding commitments from CHSRF to support a synthesis on leadership competencies. The final objective of the project is to influence policy regarding succession planning, continuing leadership development and recognition of the role of healthcare leaders in ongoing consultation related to health policy.

ACEN, through its policy committee, produced three position statements this past year that, if ratified by the members, provide policy direction related to safe, reliable healthcare, nursing human resources and research and knowledge dissemination. Members are encouraged to use these position papers to influence policy in their local environments. Further development of these position papers will continue, and new policy directions will be determined for the coming year.

ACEN members, the executive and staff continue to attend national and local meetings related to patient safety, nursing workload and health human resources. We work together with other national organizations to continue to encourage governments to provide funding and other support to implement many of the recommendations from the Nursing Sector Study. We have also been involved in various stages of the Nurse Practitioner Initiative, and will continue to work with stakeholders to move those recommendations forward. Strong leadership in this area will be required both in the short and longer term. 
Objective 2: To contribute to the alignment and advancement of the national practice, education, research and leadership agendas

In addition to our input on advanced practice and the Nurse Practitioner role, some ACEN members have been leading best practice guidelines initiatives. These guidelines will be widely disseminated and may contribute a link on the ACEN website.

ACEN continues to support research and knowledge dissemination in several different ways. As a member of the Consortium for the Advancement of Nursing Research and Innovation, we have secured funding from CHSRF to develop a framework to assess the current status of nursing research, identify gaps and areas for further development and make recommendations accordingly. ACEN has met with staff of CHSRF to discuss potential areas for knowledge synthesis, and we have attended two CHSRF prioritysetting meetings with other nurse leaders. At the meeting with the minister of health in October, we recommended a contribution of $\$ 30$ million to continue the Nursing Research Fund, which is due to expire in 2008. ACEN members individually are involved in numerous research projects, and it is hoped that the new members-only section of the website will stimulate further collaboration in research.

Objective 3: To develop strong strategic coalitions and partnerships with other healthcare leadership groups Increasingly, ACEN is being invited to join discussion tables and projects at the national level. While this is a positive sign of the value of ACEN in the eyes of many stakeholders, it is also a major challenge, given our current resources.

This year, one new activity and strategic alliance was an invitation to sit on the Nursing Advisory Committee for the Health Infoway. To date, two meetings have been held, and this will be an interesting ongoing initiative. As it develops, ACEN members may be asked to contribute ideas and advice and may also be some of the first consumers of Health Infoway products.

As mentioned earlier in this report, ACEN continues to work strategically with partners on a number of projects. These are listed below.

\section{Quality Worklife-Quality Healthcare Collaborative (QWQHC)}

This project has been somewhat slow to get going, but over the past few months the four working committees have produced some excellent material. The Indicators and Measurement working group has developed standards for key quality-of-worklife (QWL) indicators, including measures for Healthy Workplace funding, turnover, vacancy, overtime, training and development, leadership, absenteeism, safe work environment and staff satisfaction. Health systems and organizations must be required to collect, analyze and report on these standard indicators. It is proposed that these indicators be reported alongside comparable provincial indicators of wait times and patient care outcomes. The Priority Strategies for Improvement working group has 
identified four system-level strategies and 10 organization-level strategies. The PSI group is currently identifying evidence-based recommended practices for each of these strategies. It will also propose a recommended change process for each strategy. The Knowledge Exchange working group is developing a leading practice knowledge exchange vehicle that will meet the knowledge development, transfer, uptake and evaluation needs of decision-makers and researchers in order to transform the health of workplaces. Together with CHSRF, the KE working group has awarded a grant to a team of researchers to provide a current situational analysis. The results will be included in the QWQHC's final report. The Engagement and Awareness working group is creating a "burning platform" that will compel stakeholders to work together to transform the health of workplaces. It has initiated contact with the public through an initial media release and has written to federal and provincial/territorial governments to raise awareness of quality worklife issues and the QWQHC project. As well, E\&A working group members have attended several health-related conferences to represent the QWQHC project to key health professional groups.

The results of this project will provide invaluable information to ACEN members, who are continuing to improve work environments and worklife for their organizations. The project ends in 2007. The ACEN president continues to be a member of the project steering committee, and the secretary general is a member of the partners group.

\section{Healthcare leadership challenges of} interprofessional practice

ACEN, with a grant from the Office of Nursing Policy (ONP), hosted an invitational meeting of leaders from several key health professions in February 2006. Interprofessional practice is one approach considered under health human resources planning, but it is also a preferred approach to high-quality patient care and improved health outcomes. There was excellent discussion of the barriers to interprofessional practice, as well as some very good recommendations. The final report of the meeting is posted on the ACEN website and is also available from ONP.

\section{Development of healthcare leaders and managers in Canada}

This project has had numerous delays in getting off the ground. In January 2006 we were informed that HRSDC would not fund any further work in the area of health human resources. ACEN, CCHSE and CSPE are partners for this project. Patricia O'Connor and Mary Ellen Jeans continue to work on behalf of ACEN to bring the project to fruition. We have had to break it down into smaller, more focused projects, and recently have had verbal funding commitments from CHSRF and Health Canada to conduct a synthesis of leadership competencies required today and in the future. The product should be useful to ACEN members in their 
own continuing development and in mentoring more junior colleagues. The competencies may also form the basis of a mentorship initiative being considered by the ACEN Leadership committee.

\section{The Consortium for Nursing Research and Innovation}

This partnership with the Canadian Association of Schools of Nursing, Canadian Nurses Association, Canadian Association of Nurse Researchers, Canadian Nurses Foundation and ACEN is in its second year and, as reported earlier, has just received funding for its first project. It is anticipated that other funding will be sought to assist the consortium to host meetings and plan other projects.

\section{Objective 4: To support the develop-} ment of current and emerging executive nurse leaders in Canada

One way ACEN supports emerging leaders is through its annual scholarship. This year, the scholarship was awarded to Nancy Purdy, who is a PhD candidate in nursing at the University of Western Ontario.

The leadership committee continues to examine options for continuing leadership development, and this year's conference was planned to provide members with one such leadership experience. ACEN is also a partner in the February 2007 Nursing Leadership Conference, and considerable work was accomplished in this year towards planning it. As well, ACEN assisted with the review of over 300 abstracts submitted for the conference program. It will be an excellent meeting. ACEN members are encouraged to attend as a conference partner and to encourage other colleagues to attend. ACEN is planning to host a reception during the conference with the support of Johnson \& Johnson, in recognition of the Wharton Fellows program.

The Canadian Journal of Nursing Leadership continues to be our foremost leadership product. We encourage ACEN members to subscribe to the journal on behalf of their respective organizations and to contribute articles relevant to nurse leaders. The journal is very popular and has a large national and international readership.

\section{Objective 5: To provide a forum to} discuss and share ideas related to nursing practice, education, research and leadership

In addition to our annual conference and the biennial national leadership conference, ACEN is represented at a variety of other meetings and conferences related to our partners and project work. This past year has seen a substantial increase in the number of invitations ACEN receives to attend such meetings. The ACEN executive meets monthly by teleconference, as do three of the committees. From time to time the executive committee and the other working committees meet face to face. Where possible, we try to arrange such meetings in conjunction with other events attended by committee members.

Finally, as more staff time is added to the ACEN office, a quarterly update will be considered for distribution to 
members, and more material will be available to support members on the ACEN website.

\section{Conclusion}

This has been a year of continued growth in ACEN activities and continued strengthening of membership. Members are encouraged to become involved in the work of ACEN committees to further our capacity to influ- ence health policy in Canada. We have already made great strides in establishing a national voice for nurse leaders, participating in relevant policy discussions, advancing the nursing agenda and developing strong, strategic partnerships and alliances.

Our effectiveness comes from our collective knowledge, spheres of influence and strategic thinking.

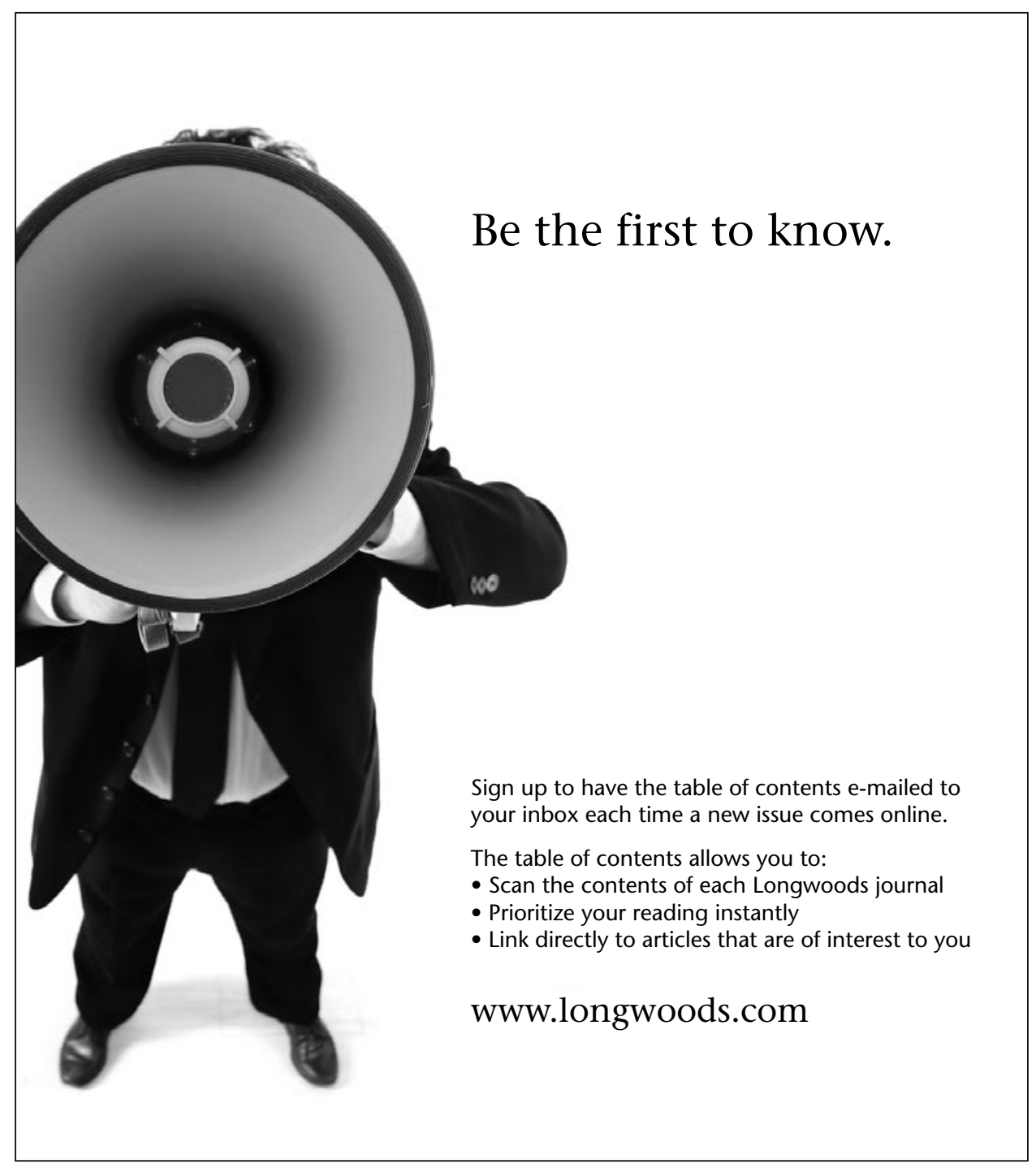

